\title{
Numerical modelling of sulphate ion concentration in wastewater from a closed cooling system
}

\author{
Pawet Regucki ${ }^{1, *}$, and Barbara Janowska ${ }^{1}$ \\ ${ }^{1}$ Wrocław University of Science and Technology, Faculty of Mechanical and Power Engineering, \\ Wybrzeże Wyspiańskiego 27, 50-370 Wrocław, Poland
}

\begin{abstract}
The paper presents a mathematical model that allows for predicting daily changes of sulphate ion concentration in water circulating in a closed cooling system consisting of condensers and cooling towers. This is an important issue because an excessive and uncontrolled increase in the concentration of $\mathrm{SO}_{4}^{2-}$ in the circulating water may cause the corrosion of concrete parts of the channels and cooling towers, as well as an increase in the concentration of calcium salts, which can accelerate the process of its deposition on the exchange surfaces inside condensers. The goal of the paper is to propose an original mathematical model, which under certain simplifications poses an analytical solution to this problem. The approach enables calculating the asymptotic value of the sulphate ion concentration in circulating water, as well as the minimal volumetric flow rate of wastewater allowing the $\mathrm{SO}_{4}{ }^{2-}$ ion concentration to be preserved below legal limits. The simplified analytical solution enables indicating the optimal volumetric flow rate of wastewater fitting the actual number of working power units. This is especially important because the daily amount of water released from the cooling system as wastewater usually reaches a level of several thousand $\mathrm{m}^{3}$ and its proper management could significantly reduce system maintenance costs.
\end{abstract}

\section{Introduction}

In conventional and thermal power plants, water is widely used in many technological processes, including, e.g.: the water-steam cycle in power boilers, the cooling installations in boiler auxiliary equipment or the cooling systems cooperating with condensers. Each of these processes requires constant access to fresh water sources with appropriate physical and chemical properties in order to maintain the continuity of electricity and heat production [1]. On the other hand, power plants are also significant producers of pollutants and wastewater $[2,3]$. The remarkable increase in the production of wastewater and its influence on the environment has resulted in the latest industrial waste regulations introduced by the Polish Ministry of Environment dated to 18 November 2014 and the EU directive [4], which impose, as of the beginning of 2016, new limits on the physical and

*Corresponding author: pawel.regucki@pwr.edu.pl 
chemical parameters of wastewater released into natural reservoirs. The increase in environmental responsibility together with high penalties for exceeding allowable wastewater limits has forced companies to look for optimal methods of industrial waste management.

One of the largest fresh water consumers in a power unit is the cooling system supporting the condensers, which are responsible for the condensation process of spent steam from the last stage of the turbine. The latent heat released in the condensation process is transferred to the water circulating in the cooling installation. Due to the fact that the amount of released heat is often calculated in hundreds of MWs, the power units must either be located close to natural water reservoirs (lakes, rivers, seas) or possess cooling equipment like fan coolers or cooling towers. An efficient cooling system is especially important as the thermodynamic conditions inside a condenser have a direct influence on the electricity production efficiency of the whole power unit. The cooling system's demand for large amounts of water on the one hand, and the recent legal regulations connected with the chemical parameters of wastewater on the other, mean that power plant operators are forced to introduce optimal methods of water resource management.

Efficient wastewater management needs scientific backgrounds and is based on mathematical models [5]. Focusing on the optimization of fresh water consumption, the Authors present an original mathematical model which allows for predicting daily changes of sulphate ion concentration in water circulating in a closed cooling system consisting of condensers and cooling towers. This is an important issue because an excessive and uncontrolled increase in the concentration of $\mathrm{SO}_{4}{ }^{2-}$ in the circulating water may cause the corrosion of concrete parts of the channels and cooling towers [6, 7], as well as an increase in the concentration of calcium salts, which can accelerate the process of its deposition on the exchange surfaces inside the condensers.

\section{Closed cooling system}

The closed cooling system is one of the largest fresh water consumers in a power plant. As a result, knowledge about the scientific processes influencing the changes in the sulphate ion concentration in the installation is essential for any attempts at establishing a mathematical model. The scheme of a closed cooling water system is presented in Fig. 1.

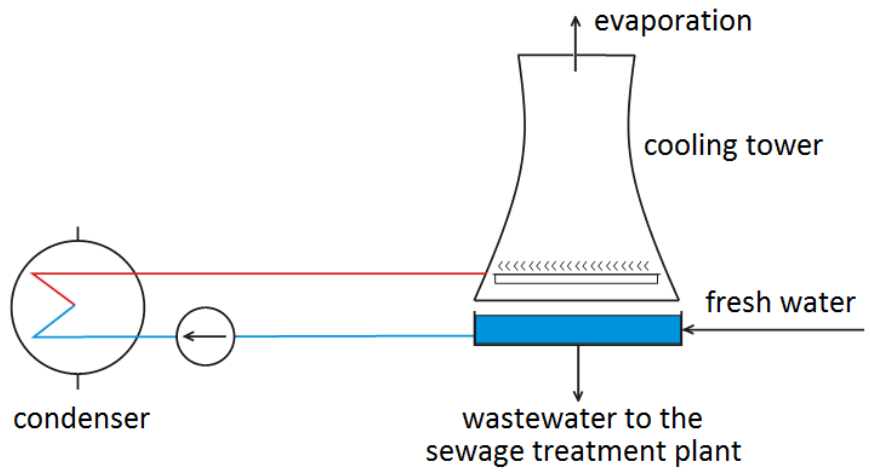

Fig. 1. Scheme of a closed system of cooling water in a power plant.

The water circulating in this system is heated in a condenser by condensing steam from the last stage of a turbine, and is then cooled down in a cooling tower. The main mechanism of water temperature decrease inside the cooling tower is connected with its partial evaporation in contact with counterflowing air [8]. This phenomenon causes a continuous decrease of the mass of the water in the installation and has a direct influence on the 
increase of the concentration of chemical compounds (among others, the abovementioned sulphate (VI) ions) in the circulating water. Due to the fact that the volume of water circulated in the system is usually at the level of tens of thousands $\mathrm{m}^{3}$, it is impossible to apply any chemical methods enabling the reduction of concentration of sulphate ions [9].

The only reasonable method to avoid the uncontrolled increase of the undesirable $\mathrm{SO}_{4}{ }^{2-}$ ion concentration in cooling water involves the periodic discharge of wastewater to a sewage treatment plant. In order to preserve a constant amount of water in the cooling installation, the missing mass of water is replenished from natural reservoirs. This action leads to the reduction of the total concentration of $\mathrm{SO}_{4}{ }^{2-}$ ions in the closed system because the fresh water usually has a lower concentration of sulphate ions in comparison to its actual concentration in the closed cooling system.

Measurements carried out in a professional power plant indicate seasonal changes in the concentration of $\mathrm{SO}_{4}{ }^{2-}$ ions (denoted by $x,\left[\mathrm{~g} / \mathrm{m}^{3}\right]$ ). Sample results are presented in Table 1 .

Table 1. Monthly changes of mean concentration of sulphate ions $x$ and mean temperature of cooling water $T$ at the reservoir of a cooling tower.

\begin{tabular}{|c|c|c|c|c|c|c|c|c|c|c|c|c|}
\hline Month & I & II & III & IV & V & VI & VII & VIII & IX & X & XI & XII \\
\hline$T,{ }^{\circ} \mathrm{C}$ & 15.7 & 14.0 & 14.5 & 17.4 & 19.1 & 19.9 & 21.2 & 22.0 & 20.6 & 20.4 & 16.7 & 16.9 \\
\hline$x, \mathrm{~g} / \mathrm{m}^{3}$ & 175.0 & 160.0 & 190.2 & 206.4 & 252.0 & 303.7 & 313.0 & 316.2 & 253.6 & 276.4 & 190.7 & 195.4 \\
\hline
\end{tabular}

The presented data indicate that the mean monthly concentration of $\mathrm{SO}_{4}{ }^{2-}$ ions changes over the course of the year. There are two factors which significantly influence this situation: the high intensity of water evaporation in the cooling tower during the summer and the reduction of the operation parameters of the cooling tower in winter. It is observed that in summer about $90 \%$ of the transported heat is released through the evaporation process, which causes approximately $1 \%$ of the mass of circulating water to evaporate in the cooling towers [8]. On the other hand, in winter the intensity of water evaporation is limited not only by the low ambient temperature but also for technological reasons forcing the temperature of the cooling water in the installation to amount to no less than $12^{\circ} \mathrm{C}$. In order to preserve the temperature of the circulating water at above $12^{\circ} \mathrm{C}$ in winter only part of it is cooled down in the cooling towers. The intensity of water loss is reflected in the highest value of $\mathrm{SO}_{4}{ }^{2-}$ ion concentration in July and August (up to $\sim 320 \mathrm{~g} / \mathrm{m}^{3}$ ) in opposition to the lowest concentration in February (approx. $160 \mathrm{~g} / \mathrm{m}^{3}$ ). Keeping in mind that legal regulations allow for a much higher $\mathrm{SO}_{4}{ }^{2-}$ ion concentration in wastewater (maximally $x_{\text {limit }}=500 \mathrm{~g} / \mathrm{m}^{3}[5]$ ), the operator of the closed cooling system releases more sewage than required. This situation provides an opportunity to optimize wastewater management in order to reduce the operating costs of the system.

\section{Results and discussion}

\subsection{Mathematical model}

Analysing the thermal-flow processes in a closed cooling system, the Authors indicate three main physical mechanisms leading to changes in the sulphate ion concentration in circulating water:

- evaporation of water in cooling towers, $q_{\mathrm{v}, \mathrm{ct}}$,

- replenishment of fresh water, $q_{\mathrm{v}, \mathrm{fw}}$,

- discharge of wastewater to a sewage treatment plant, $q_{\mathrm{v}, \mathrm{dw}}$. 
The relationship between these three abovementioned processes is schematically presented in Figure 2.

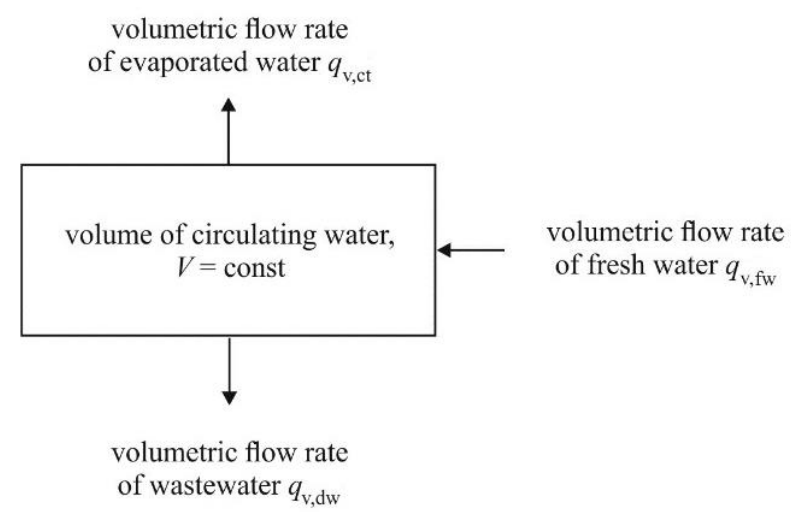

Fig. 2. Schematic balance of circulating water in a closed cooling system.

Due to the fact that the total volume of circulating water in the closed system $V$ is conserved, the mass conservation law for volumetric flow rates must be satisfied:

$$
q_{\mathrm{v}, \mathrm{fw}}=q_{\mathrm{v}, \mathrm{ct}}+q_{\mathrm{v}, \mathrm{dw}}
$$

The analysis of losses and replenishment of water in the closed system has allowed the Authors to formulate a differential equation describing the changes of $\mathrm{SO}_{4}{ }^{2-}$ concentration in circulating water $(t-$ time in days):

$$
V \frac{d x(t)}{d t}=-q_{\mathrm{v}, \mathrm{dw}}(t) \cdot x(t)-q_{\mathrm{v}, \mathrm{ct}}(t) \cdot x_{\mathrm{ct}}+q_{\mathrm{v}, \mathrm{fw}}(t) \cdot x_{\mathrm{fw}}(t)
$$

where:

$x(t)$ - current concentration of sulphate ions in circulating water,

$x_{\mathrm{ct}}-$ sulphate ion concentration in vapour released in the cooling tower,

$\mathrm{x}_{\mathrm{fw}}(t)$ - concentration of sulphate ions in fresh water.

All the concentrations are in $\mathrm{g} / \mathrm{m}^{3}$, the volumetric flow rates in $\mathrm{m}^{3} / \mathrm{d}$, and the total volume $V$ in $\mathrm{m}^{3}$.

Equation (2) can be analytically solved under the assumptions that volumetric flow rates $q_{\mathrm{v}, \mathrm{dw}}$ and $q_{\mathrm{v}, \mathrm{ct}}$ are constant over time, sulphate ion concentration in fresh water $x_{\mathrm{fw}}$ is fixed and vapour leaving the cooling tower is chemically clean $\left(x_{\mathrm{ct}}=0 \mathrm{~g} / \mathrm{m}^{3}\right)$. This reduces (2) to the form of a first order ordinary differential equation with constant coefficients $a$ and $b$ :

$$
\frac{d x(t)}{d t}+a \cdot x(t)-b=0
$$

where: $a=q_{\mathrm{v}, \mathrm{dw}} / V$ and $b=q_{\mathrm{v}, \mathrm{fw}} \cdot x_{\mathrm{fw}} / V$. The solution of (3) is the function $x(t)$, which describes change in $\mathrm{SO}_{4}{ }^{2-}$ concentration over time:

$$
x(t)=\frac{b}{a}+\left(x_{0}-\frac{b}{a}\right) \cdot e^{-a t}
$$

where $x_{0}$ is the initial $\mathrm{SO}_{4}{ }^{2-}$ ion concentration in the closed cooling system.

It is worth noting that the model does not have physical sense for coefficient $b=0$ because in this case either the mass conservation law (2) is not satisfied ( $q_{\mathrm{v}, \mathrm{fw}}$ is zero) or the concentration of sulphate ions in fresh water $\mathrm{x}_{\mathrm{fw}}$ amounts to zero. On the other hand, 
the coefficient $a$ must also have a nonzero value (which means that $q_{\mathrm{v}, \mathrm{dw}} \neq 0$ ), because otherwise the equation (2) is reduced to the form:

$$
\frac{d x(t)}{d t}-b=0
$$

which has the linear solution $x(t)=b \cdot t+x_{0}$ and the concentration $x(t)$ tends to infinity over time.

The $\mathrm{SO}_{4}{ }^{2-}$ ion concentration in fresh water varies between $20-40 \mathrm{~g} / \mathrm{m}^{3}$ depending on local chemical conditions; thus, in the model, the Authors have used $x_{\mathrm{fw}}=40 \mathrm{~g} / \mathrm{m}^{3}$. Figure 3 presents an example of solutions (4) obtained for $q_{\mathrm{v}, \mathrm{ct}}=45600 \mathrm{~m}^{3} / \mathrm{d}$ and the total volume of the circulating water equalling $V=90000 \mathrm{~m}^{3}$.

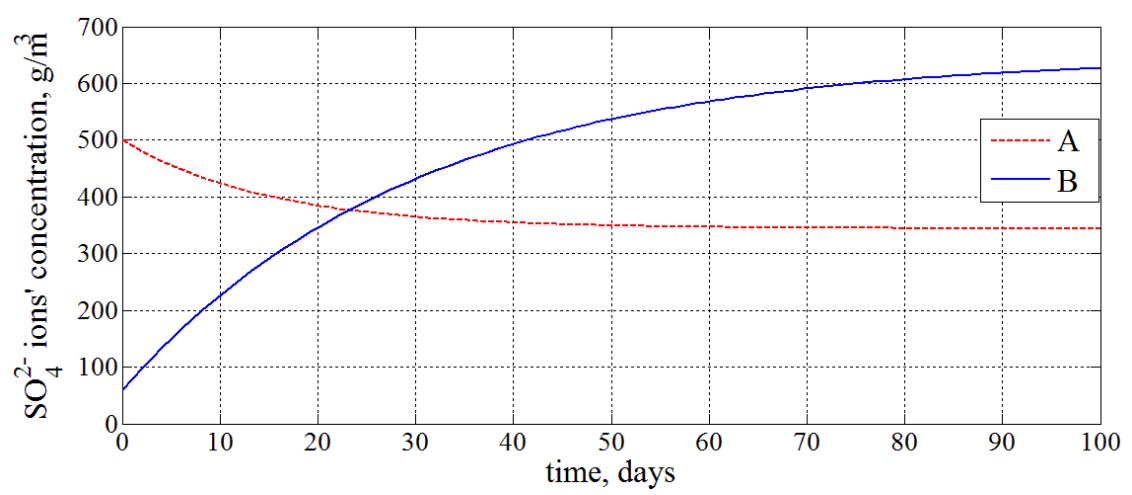

Fig. 3. Example of analytical solutions of (4) for different initial conditions: A (red dashed line) - $x_{0}=500 \mathrm{~g} / \mathrm{m}^{3}$ and $q_{\mathrm{v}, \mathrm{dw}}=6000 \mathrm{~m}^{3} / \mathrm{d}$; B (blue solid line) $-x_{0}=60 \mathrm{~g} / \mathrm{m}^{3}, q_{\mathrm{v}, \mathrm{dw}}=3000 \mathrm{~m}^{3} / \mathrm{d}$.

The curves A and B in Figure 3 present two possible solutions of (4) depending on the initial condition $x_{0}$ and values of the $a$ and $b$ coefficients. For a fixed volumetric flow rate of evaporated water inside cooling towers $q_{\mathrm{v}, \mathrm{ct}}$ and a fixed total volume of water circulating in installation $V$, the value of the discharge of wastewater to a sewage treatment plant $q_{\mathrm{v}, \mathrm{dw}}$ has a decisive influence on the shape of the presented plots. In case $A$, the flow rate $q_{\mathrm{v}, \mathrm{dw}}=6000 \mathrm{~m}^{3} / \mathrm{d}$ causes a decrease in the initial $\mathrm{SO}_{4}{ }^{2-}$ ion concentration over time to the level $\sim 350 \mathrm{~g} / \mathrm{m}^{3}$, while in case B the low value of $q_{\mathrm{v}, \mathrm{dw}}=3000 \mathrm{~m}^{3} / \mathrm{d}$ causes the increase of $x(t)$ over time up to $\sim 650 \mathrm{~g} / \mathrm{m}^{3}$. It is worth noting that both curves have the asymptotic solutions $x_{\infty}$ if time tends to infinity. The exact value of $x_{\infty}$ can be calculated for both cases from the limit:

$$
x_{\infty}=\lim _{t \rightarrow \infty} x(t)=\lim _{t \rightarrow \infty}\left[\frac{b}{a}+\left(x_{0}-\frac{b}{a}\right) \cdot e^{-a t}\right]=\frac{b}{a}
$$

For the presented examples, the asymptotic value $x_{\infty}$, calculated for formula (6), is equal to $344 \mathrm{~g} / \mathrm{m}^{3}$ and $648 \mathrm{~g} / \mathrm{m}^{3}$ respectively. From the mathematical point of view, the fixed value of $x$ is reached also when the bracket $\left(x_{0}-b / a\right)$ in formula (4) amounts to zero. In this case, $x(t)$ and $x_{0}$ are simply equal to $x_{\infty}$.

\subsection{Numerical study}

It is worth comparing the simplified analytical solution (4) of the presented mathematical model with its numerical study. To do so, numerical methods were used to solve the time-dependent equation (2) satisfying mass conservation law (1). Equation (2) was discretized using the updated Euler method [10]: 


$$
\begin{gathered}
p_{i+1}=x_{i}+\Delta t \cdot\left(-\frac{q_{\mathrm{v}, \mathrm{dw}}}{V} \cdot x_{i}+\frac{\left(q_{\mathrm{v}, \mathrm{dw}}+q_{\mathrm{v}, \mathrm{ct}}\right)}{V} x_{\mathrm{fw}}\right) \\
x_{i+1}=x_{i}+\frac{\Delta t}{2} \cdot\left(-\frac{q_{\mathrm{v}, \mathrm{dw}}}{V} \cdot\left(x_{i}+p_{i+1}\right)+2 \frac{\left(q_{\mathrm{v}, \mathrm{dw}}+q_{\mathrm{v}, \mathrm{ct}}\right)}{V} x_{\mathrm{fw}}\right)
\end{gathered}
$$

where $x_{i}=x\left(t_{i}\right)$ is the numerical solution for $t_{i}=t_{0}+\Delta t \cdot i,(i=0,1, \ldots)$ and $\Delta t$ is a time step. In order to estimate the accuracy of the numerical solutions obtained from formula (7), they were compared with analytical functions (4) derived for the set of parameters $\left\{x_{0}, x_{\mathrm{fw}}, q_{\mathrm{v}, \mathrm{dw}}, q_{\mathrm{v}, \mathrm{ct}}, V\right\}$ analysed in cases $\mathrm{A}$ and B (presented in Fig. 3). The relative error $E_{\text {rel }}$ was calculated according to the formula:

$$
E_{\text {rel }}=\frac{\left|x_{\text {anal }}\left(t_{\mathrm{i}}\right)-x_{\text {num }}\left(t_{\mathrm{i}}\right)\right|}{x_{\text {anal }}\left(t_{\mathrm{i}}\right)} \cdot 100 \%
$$

where $x_{\text {anal }}$ and $x_{\text {num }}$ denote the analytical and numerical solution respectively. The comparison of $E_{\text {rel }}$ calculated for cases A and B is presented in Fig. 4. In both analysed examples, the relative error is less than $0.012 \%$ and decreases at the ends of the interval.

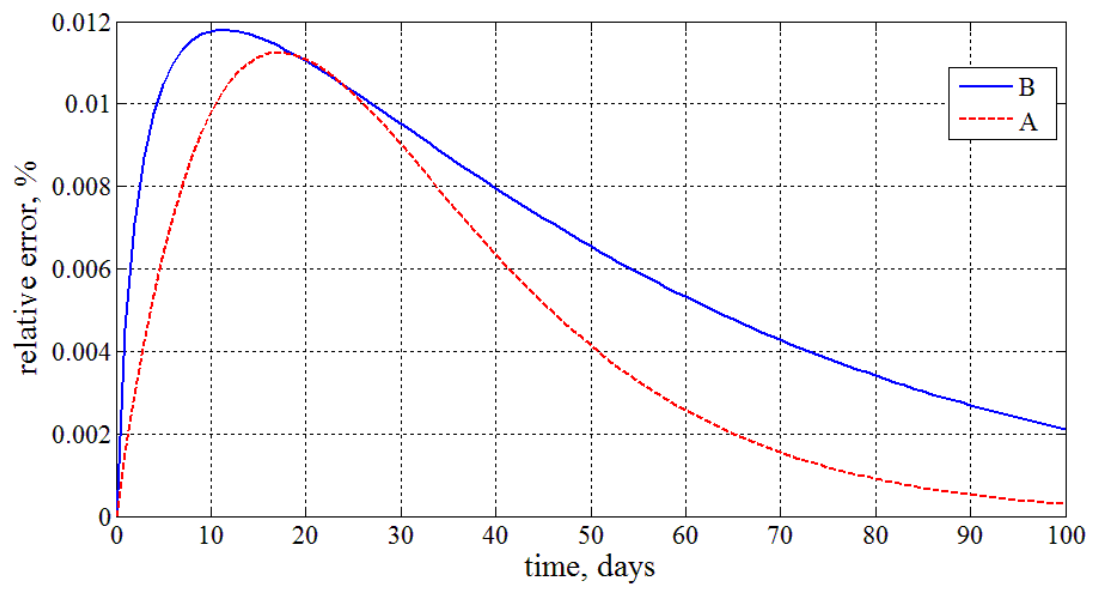

Fig. 4. Relative error $E_{\text {rel }}$ of analytical and numerical solutions calculated from formula (8) for cases A and B presented in Fig. 3.

The measurements conducted on the cooling water installation have shown that despite the fact that mean values of volumetric flow rates are conserved, its daily values can vary by even $\pm 15 \%$. It is worth mentioning that the concentration of sulphate ions in fresh water $x_{\mathrm{fw}}$ is rather stable and depends on the chemical properties of local water reservoirs. In order to assess the suitability of the analytical solution (4) to predict the change of $\mathrm{SO}_{4}{ }^{2-}$ ion concentration in a real installation, the numerical scheme (7) was modified to take into account the possibility of the daily changes of the $q_{\mathrm{v}, \mathrm{dw}}$ and $q_{\mathrm{v}, \mathrm{ct}}$ parameters:

$$
\begin{aligned}
p_{i+1}= & x_{i}+\Delta t \cdot\left(-\frac{q_{\mathrm{v}, \mathrm{dw}}\left(t_{i}\right)}{V} \cdot x_{i}+\frac{\left(q_{\mathrm{v}, \mathrm{dw}}\left(t_{i}\right)+q_{\mathrm{v}, \mathrm{ct}}\left(t_{i}\right)\right)}{V} x_{\mathrm{fw}}\right) \\
x_{i+1}= & x_{i}+\frac{\Delta t}{2} \cdot\left(-\frac{\left(q_{\mathrm{v}, \mathrm{dw}}\left(t_{i}\right) \cdot x_{i}+q_{\mathrm{v}, \mathrm{dw}}\left(t_{i+1}\right) \cdot p_{i+1}\right)}{V}+\ldots\right. \\
& \left.\ldots+\frac{\left(q_{\mathrm{v}, \mathrm{dw}}\left(t_{i}\right)+q_{\mathrm{v}, \mathrm{dw}}\left(t_{i+1}\right)+q_{\mathrm{v}, \mathrm{ct}}\left(t_{i}\right)+q_{\mathrm{v}, \mathrm{ct}}\left(t_{i+1}\right)\right)}{V} x_{\mathrm{fw}}\right)
\end{aligned}
$$


An example of a numerical solution including the fluctuation of $q_{\mathrm{v}, \mathrm{dw}}$ and $q_{\mathrm{v}, \mathrm{ct}}$ at a level of $\pm 15 \%$ is presented in Figure 5. The calculations were done for the parameters used in case A and compared with the analytical solution (4) for mean values of $q_{\mathrm{v}, \mathrm{ct}}=45600 \mathrm{~m}^{3} / \mathrm{d}$ and $q_{\mathrm{v}, \mathrm{dw}}=6000 \mathrm{~m}^{3} / \mathrm{d}$.

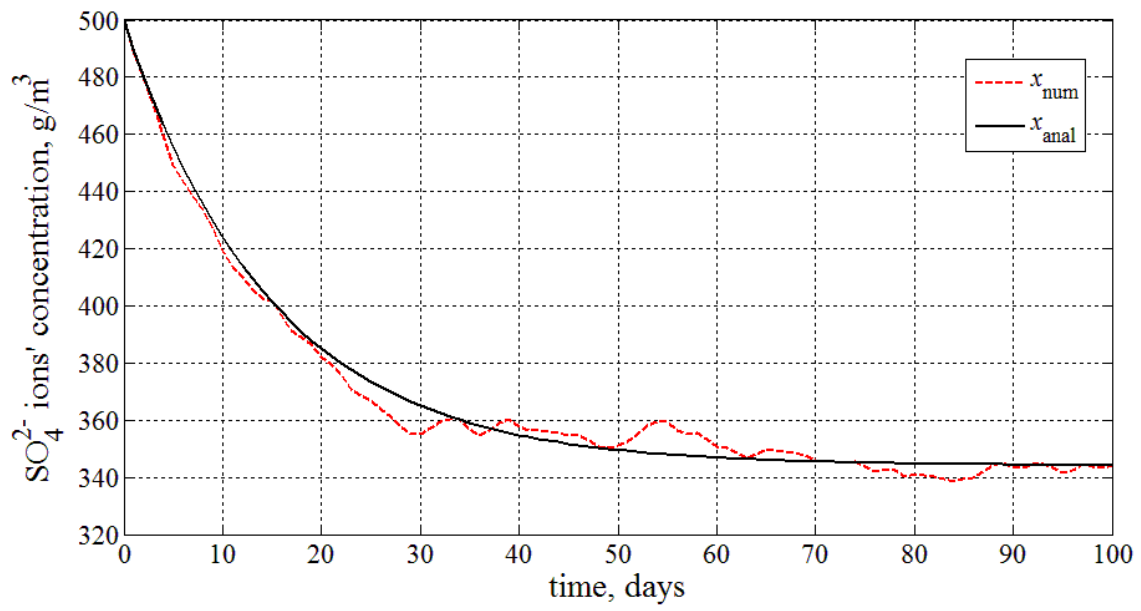

Fig. 5. Comparison of analytical solution $x_{\text {anal }}$ (black solid curve) and numerical results $x_{\text {num }}$ (red dashed curve) obtained from formula (9) for $x_{0}=500 \mathrm{~g} / \mathrm{m}^{3}, q_{\mathrm{v}, \mathrm{dw}}=6000 \mathrm{~m}^{3} / \mathrm{d}, q_{\mathrm{v}, \mathrm{ct}}=45600 \mathrm{~m}^{3} / \mathrm{d}$ and $x_{\mathrm{fw}}=40 \mathrm{~g} / \mathrm{m}^{3}$.

The relative error for the abovementioned example is presented in Figure 6. The presented data shows that the maximum value of $E_{\text {rel }}$ is approximately $3.3 \%$, which indicates very high agreement of the analytical solution with the numerical data even if fluctuations of the volumetric flow rates $\left\{q_{\mathrm{v}, \mathrm{dw}}, q_{\mathrm{v}, \mathrm{ct}}\right\}$ are taken into account.

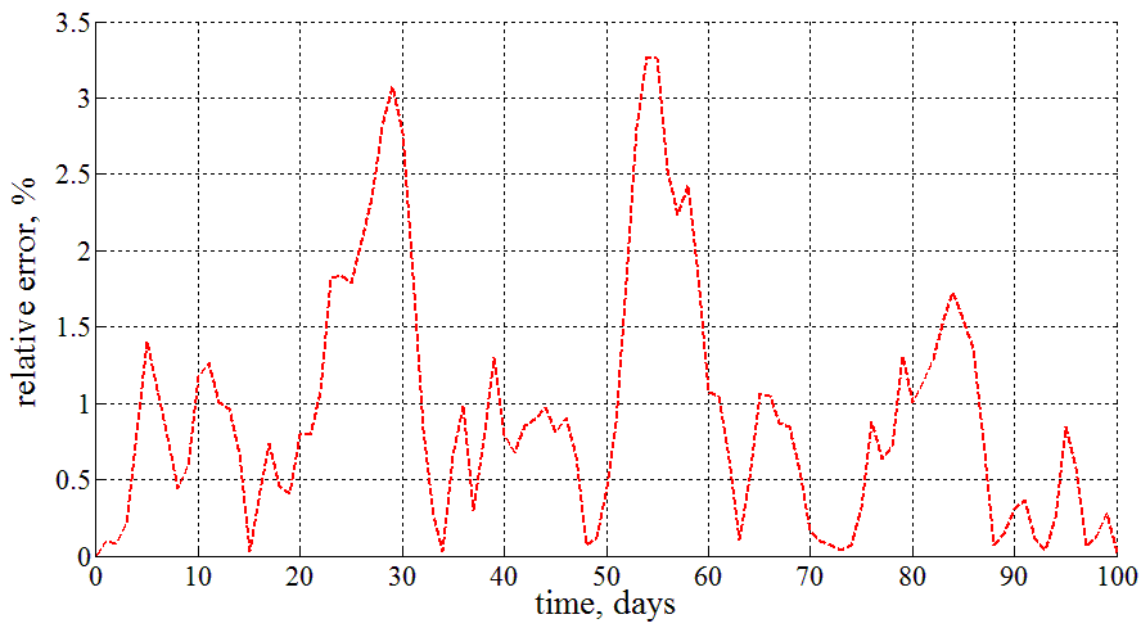

Fig. 6. Relative error calculated from formula (8) for solutions presented in Figure 5.

\section{Closing remarks}

The mathematical model created by the Authors is the first in literature which describes the changes in the sulphate ion concentration in a closed cooling system. The goal of the model lies in the fact that its analytical solution (4) enables estimating the minimum 
requirement of the wastewater volumetric flow rate $q_{\mathrm{v}, \mathrm{dw}}$ in order to satisfy the current legal regulations of $\mathrm{x}_{\text {limit }}=500 \mathrm{~g} / \mathrm{m}^{3}$. Example values of minimal wastewater volumetric flow rate, parametrized by $\mathrm{SO}_{4}{ }^{2-}$ ion concentration in fresh water $x_{\mathrm{fw}}$ and the volumetric flow rate of vapour from cooling towers $q_{\mathrm{v}, \mathrm{ct}}$, are presented in Table 2 .

Table 2. Minimal values of volumetric flow rates $q_{\mathrm{v}, \mathrm{dw}}$ (in $\mathrm{m}^{3} / \mathrm{d}$ ) required to satisfy legal regulations imposed on sulphate ion concentration $x$ in wastewater from a power plant $x_{\text {limit }}=500 \mathrm{~g} / \mathrm{m}^{3}$.

\begin{tabular}{|c|c|c|c|}
\hline $\begin{array}{r}\mathrm{SO}_{4}{ }^{2-} \text { ion concentration } \\
q_{\mathrm{v}, \mathrm{ct}},\left[\mathrm{m}^{3} / \mathrm{d}\right]\end{array}$ & 20 & 30 & 40 \\
\hline 35000 & 1459 & 2235 & 3044 \\
\hline 40000 & 2554 & 2554 & 3479 \\
\hline 45600 & 1900 & 2911 & 3966 \\
\hline
\end{tabular}

This knowledge could help operators and decision makers to introduce planned and cost-effective wastewater management in power plants, reducing the consumption of fresh water as well as the amount of industrial waste discharged into the environment. In order to automate the wastewater management process, it is possible to implement the mathematical model into a computer program that could be included in the power plant's monitoring system.

\section{References}

1. J. Stańda, Woda do kotłów parowych i obiegów chłodzacych siłowni cieplnych (WNT, Warszawa, 1999)

2. S. Fleischli, Blog: Message to EPA: Time to Modernize America's Power Plants Cooling Systems Included. https://www.nrdc.org/experts/steve-fleischli/message-epatime-modernize-americas-power-plants-cooling-systems-included (Last cited 4 January 2016)

3. W. Hermanowicz et al., Fizyczno - chemiczne badanie wody i ścieków (Arkady, Warszawa, 2010)

4. Council Directive 91/271 / EEC of 21 May 1991. Urban Waste Water Treatment (Acts. Office. EC L 135, 05.30.1991, p. 40, as amended. d.; Acts. Office. Polish special edition, ch. 15, v. 2, p. 26), the Directive of the European Parliament and of the Council 2010/75/EU of 24 November 2010. on industrial emissions (integrated pollution prevention and control) (recast) (OJ. office . EC L 334, 17.12.2010, p. 17, as amended. d)

5. I. Skoczko, P. Ofman, E. Szatyłowicz, R. Och. Środ. 18 (2016)

6. F. Bellmann, W. Erfurt, H-M. Ludwig, Cement \& Concrete Comp. 341 (2012)

7. J. Condor, K. Asghari, D. Unatrakarn, DOI: 10.1016/j.egypro.2011.02.506 (2011)

8. L. D. Berman, Evaporative cooling of circulating water (Pergamon Press, New York, 1961)

9. R. Silva, L. Luciana, J. Rubio, Minerals Eng. 23, 15 (2010)

10. J. H. Mathews, K. D. Fink, Numerical methods using Matlab (Prentice Hall, New York, 2004) 